\title{
Emotionality related to maternal cannibalism in BALB and C57BL mice*
}

\author{
WAYNE POLEY \\ University of Alberta, Edmonton, Alberta, Canada T6G $2 E 9$
}

\begin{abstract}
Twenty-four female mice from two inbred strains, BALB and C57BL, were tested for emotional behavior. Half of the animals had successfully raised their first litter to weaning, while the other half had eaten their first litter. Cannibalistic females of both strains were found to be more prone to auditory stress than controls. However, the relationship between emotional defecation and cannibalism was found to interact with strain, suggesting an optimum level of arousal.
\end{abstract}

The casual observations of animal breeders suggest that, in a number of species, stress may cause females with offspring to neglect, kill, or eat their young. This finding is a cuase of some concern in mink ranching, for example, and studies have been made of this problem in mink (Menear, 1968). Maternal cannibalism is commonly observed when offspring are cross-fostered (Pilgrim \& Parks, 1968; Poley \& Royce, 1970). Psychologists have also directed some attention to mother-offspring interaction in rodents, with particular interest in its effects on offspring behavioral development (Ressler, 1962, 1963; Ader \& Grota, 1970). However, the specific problem of maternal cannibalism has not been intensively studied. The purpose of the present study was to determine whether cannibalistic female mice differ emotionally from noncannibalistic females.

\section{METHOD}

\section{Subjects}

The Ss were 24 female mice obtained from the Laboratory Animal Service of the University of Alberta. Twelve were from the BALB/ALB strain and 12 were from the C57BL/ALB strain. Mice from the C57BL/ALB strain were developed from original Jackson Laboratory inbred stock at the University of Washington and the University of Alberta. Mice from the BALB/ALB strain were developed from Jackson Laboratory stock at the University of Wisconsin and University of Alberta. Both strains had reached over 30 generations of brother-sister matings outside the Jackson Laboratory at the time of the study. All mice tested had produced one litter. Half of the mice in each strain gave indications that they had eaten part or all of their first litter, while the other haif successfully raised their first litter to weaning. Ss began testing at an average age of 131 days, 27 days after the birth of their first litter.

\section{Procedure}

Ss were administered a battery of tests of emotionality requiring 1 month for completion. Fuller details may be obtained elsewhere (Royce, Poley, \& Yeudall, 1973; Poley \& Royce, 1973). The tests, in sequence of administration, included avoidance conditioning, individual emergence, removal, activity wheels, open field, straightaway, pole, cell, hole-in-wall, pipe, and activity with bell. This yielded 35 measures, primarily

\footnotetext{
*The author would like to thank J. R. Royce for making his laboratory facilities available for this study and Dorothy Richer for collecting the data.
}

indices of activity and elimination, which were used in the analysis.

In summary, the tests and measures used may be described as follows in order of their administration.

Avoidance Conditioning. This is a two-way shuttlebox with footshock for UCS and electronic buzzer as CS. Parameters used were those determined by Royce (1966) as optimal for producing strain difference. Footshock is set at $400 \mathrm{~V}$, with CS duration of $3 \mathrm{sec}$ and CS/UCS interval at $3.5 \mathrm{sec}$. Intertrial interval is $120 \mathrm{sec}$. Ss are given 25 consecutive trials per day for 3 days. Two measures are obtained: total correct avoidances and intertrial activity.

Individual Emergence. In the individual emergence test, the lid of the home cage is removed in an observation box and one measure is taken: latency to emerge into the environment.

Removal Rating. In this test the E attempts to remove the animal from its home cage. The $S$ is rated on a scale from 0 (no attempt to escape) to 3 (extremely manic).

Activity Wheel. A standard activity wheel is proportioned to the size of the species under study. Ss are housed for 2 days in a small living cage adjacent to the wheel, with free access to it. Two consecutive nocturnal readings are averaged, as are two consecutive diurnal readings.

Open Field. This is one of the most widely used measures of rodent emotionality. It consists of a white circular field, $4 \mathrm{ft}$ in diam, divided into concentric circles, with intersecting lines radiating outward from the center of the field. Five measures are taken, based on averages from 2 consecutive days of testing: latency to leave the start section, activity during a 2-min trial, penetration into the center of the field, defecation, and urination.

Straightaway. This is an elevated runway, $50 \mathrm{in}$, long and 1.5 in. wide. Ss are given a 3-min trial each day for 2 consecutive days. Measures recorded are latency to leave the start section, activity, defecation, and urination.

Pole. In this test the $S$ is placed on a wire mesh platform on top of a metal pole $34 \mathrm{in}$. high. The animal is able to descend of his own volition by a vertical wire mesh ladder. Measures, averaged over a 2-day period, include latency to leave the top, latency to descend, defecation, and urination.

Cell and Hole-in-Wall. In the cell test, the $S$ is placed in a small compartment $(4 \times 4 \times 3$ in.) with opaque lid and is able to emerge through a small door into a light compartment of the same size. The hole-in-wall test involves emergence from light compartment to dark compartment. Cell is tested on one day to yield morning and evening measures: latency, defecation, and urination. Hole-in-wall is tested the next day (also morning and afternoon) to yield the same three measures.

Pipe. The pipe measure consists of two illuminated white plastic boxes connected by an opaque pipe 2 in. in diam. Ss are tested under 14-h food deprivation and obtain two $25-\mathrm{mg}$ food pellets upon entering the goalbox. At each test session, the $\mathrm{S}$ 

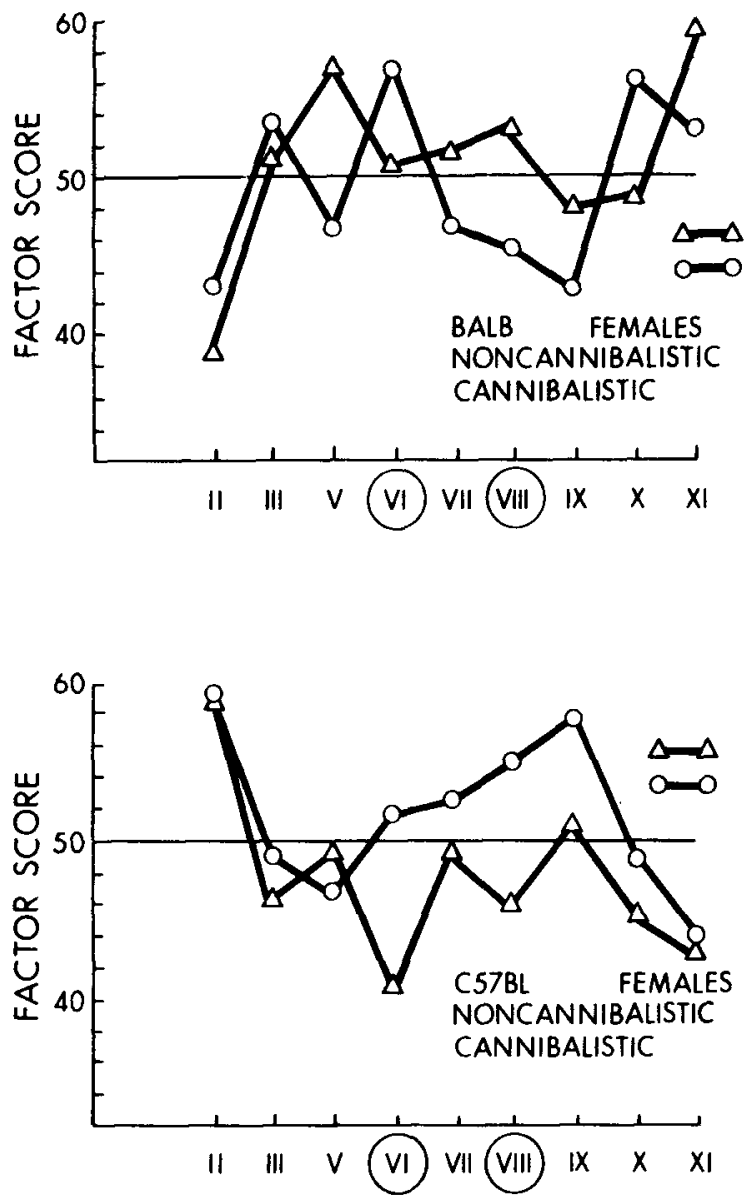

Fig. 1. Emotionality profiles for cannibalistic and noncannibalistic females from the BALB and C57BL strains.

runs from one goalbox to the other and back again to yield two trials. Testing is done on 2 consecutive days. This gives six measures: latency to enter pipe (Trial 1), latency to emerge from pipe (Trial 1), latency to enter pipe (Trials 2, 3, and 4 averaged), latency to emerge from pipe (Trials 2, 3, and 4 averaged), defecation, and urination. The separation of Trial 1 from Trials 2,3 , and 4 is based on the fact that the animal is unaware of the reward on the first trial; a learning component would be expected to influence later trials.

Circular Activity with Bell. This apparatus is a circular activity cage $18 \mathrm{in}$. in diam. Beneath the cage is a large bell. The $S$ is tested on 1 day, during which a 5 -min period of silence is followed by a 5 -min period of bell ringing; then this sequence is repeated. This gives four measures: activity with bell turned off, activity during bell, defecation, and urination.

Factor scores were obtained by the regression method using the formula $F=A^{1} R^{1} Z$, where $A$ is an $n$ by $m$ factor structure matrix (from Royce, Poley, \& Yeudall, 1973), $R$ is an $\mathbf{n}$ by $n$ correlation matrix, and $\mathrm{Z}$ is the $\mathrm{n}$ by $\mathrm{N}$ matrix of standard scores. The Royce et al (1973) study yielded 10 interpretable factors of emotionality. All of these factors, with the exception of underwater swimming (Factor IV), were assessed in the present study. Factor IV is apparatus dependent (lacks behavioral generality) and was therefore deleted from the test sequence. The factor analytic approach may be considered as a means of meaningfully reducing the 35 measures from 11 tests to 9 general traits or factors.

\section{RESULTS AND DISCUSSION}

Scores on the nine factors are given in Fig. 1. Scores are based on a mean of 50 and standard deviation of 10 . Factors, in sequence, have been interpreted as motor discharge (II), acrophobia (III), tunneling-1 (V), audiogenic reactivity (VI), food motivation (VII), autonomic balance (VIII), territorial marking (IX), general activity $(\mathrm{X})$, and tunneling-2 (XI). Factor I relates to weight measures only and, therefore, was not included as part of the behavioral profile. The relationship between factors and the variables which load on the factors is outlined in Table 1 .

Analysis of variance of factor scores revealed the following. Mice of the C57BL strain have higher scores on Factor II, motor discharge, than BALB mice, i.e., are more active and therefore freeze less under light $(\mathrm{F}=97.4, \mathrm{df}=1 / 20, \mathrm{p}<.01)$. BALB females have higher scores on Factor XI, tunneling- $2 \quad(F=14.0$, $\mathrm{p}<.01$ ). That is, they freeze more in tests requiring passage through a tunnel or doorway than C57BL mice, consistent with the results of Factor II.

For effects related to cannibalism, the major result is a significant difference on Factor VI, audiogenic reactivity. That is, the cannibalistic females are more active under an auditory stressor $(\mathrm{F}=5.4, \mathrm{p}<.05)$. This also suggests that the initial cause of the cannibalism may have been auditory disturbances in the breeding colony. When we are dealing with such small sample sizes, the examination of lower probability levels may also be justifiable. Of particular interest is Factor VIII, autonomic balance, where the genotype-cannibalism interaction approaches significance $(\mathrm{F}=3.8, \mathrm{p}<.10)$. This interaction shows up as a reversal, with cannibalistic females having lower scores in the BALB strain but higher scores in the C57BL strain. Factor VIII, autonomic balance, designates emotional elimination, primarily defecation, in test situations where the animal is exposed to illumination in an open area. Tests which have been found to be indicative of this factor are primarily open field, straightaway (an elevated runway), and pole.

In interpreting these effects we must recognize, first of all, that the study is essentially correlational in nature. (A more conclusive follow-up would manipulate emotionality with auditory or visual stressors.) With this limitation in mind, we can say that the present study indicates that mice of both strains, which are relatively prone to auditory stress, are also more likely to kill or eat their offspring. This is all the more significant if we consider the extensive literature on auditory stress and audiogenic seizures in the mouse and the behavior genetic analyses of this phenomenon (e.g., Schlesinger \& Griek, 1970). From the genetic standpoint this would also indicate that, where environmental stimulation is not vigorously controlled in a rodent breeding colony, those who handle animals are unknowingly conducting 
Table 1

Loadings of Variables on Factors (Alpha Factoring, Varimax Rotation)*

\begin{tabular}{|c|c|c|c|c|c|c|c|c|c|}
\hline \multirow[b]{2}{*}{ Measure } & \multicolumn{9}{|c|}{ Factor } \\
\hline & 2 & 3 & 5 & 6 & 7 & 8 & 9 & 10 & 11 \\
\hline Average Correct Avoidances & 11 & -08 & 03 & 02 & 04 & 00 & 01 & -08 & -05 \\
\hline Average Intertrial Activity & 01 & -03 & 06 & 17 & 03 & 07 & -07 & 00 & -04 \\
\hline $\begin{array}{l}\text { Individual Emergence } \\
\text {. }\end{array}$ & -02 & 04 & -04 & -04 & -02 & -01 & 00 & 01 & 03 \\
\hline Removal & 17 & 07 & -10 & -02 & 02 & -13 & 11 & 04 & -14 \\
\hline Activity Wheel, Night & -02 & -09 & 00 & 09 & 11 & 00 & -09 & 38 & 05 \\
\hline Activity Wheel, Day & -10 & -03 & 03 & -01 & 36 & -01 & 01 & 25 & 12 \\
\hline Open-Field Latency & -66 & 11 & -13 & -09 & -10 & 01 & -03 & 02 & 06 \\
\hline Open-Field Activity & 76 & 08 & -06 & -01 & -08 & -05 & 04 & 00 & -06 \\
\hline Open-Field Penetration & 57 & -07 & -15 & -01 & -15 & -10 & 10 & 02 & -01 \\
\hline Open-Field Defecation & -09 & 06 & 02 & 07 & -05 & 47 & 33 & 07 & -05 \\
\hline Open-Field Urination & 06 & 03 & 02 & -01 & 01 & 15 & 32 & 07 & -04 \\
\hline Straightaway Latency & -46 & 31 & -14 & -07 & -01 & -12 & 03 & 09 & 01 \\
\hline Straightaway Activity & 48 & -10 & -05 & 11 & -06 & 01 & -08 & -02 & -16 \\
\hline Straightaway Defecation & 03 & 03 & -03 & 07 & -04 & 64 & 20 & -15 & 00 \\
\hline Straightaway Urination & -04 & -09 & 09 & 04 & -02 & 08 & 53 & -16 & -07 \\
\hline Pole Top & -20 & 69 & -05 & 01 & 02 & -04 & -05 & 09 & -01 \\
\hline Pole Descend & -09 & 47 & 40 & -04 & -12 & -07 & -10 & 04 & 23 \\
\hline Pole Defecation & -04 & 81 & 10 & -02 & 10 & 12 & 07 & -01 & -01 \\
\hline Pole Urination & 07 & 05 & 00 & 00 & -05 & 13 & 42 & -11 & 06 \\
\hline Cell Latency & -10 & 05 & 10 & 09 & 05 & -01 & -06 & 19 & 40 \\
\hline Cell Defecation & -07 & -03 & 27 & 03 & -04 & 31 & 09 & -04 & 10 \\
\hline Cell Urination & 01 & -03 & 59 & -02 & -04 & -01 & 18 & -10 & 11 \\
\hline Hole Latency & -09 & 01 & 21 & -01 & -02 & 04 & -08 & 01 & 50 \\
\hline Hole Defecation & -03 & 22 & 36 & 12 & 17 & 19 & 03 & -11 & -02 \\
\hline Hole Urination & -10 & -07 & 37 & 18 & 10 & 00 & 20 & -28 & -13 \\
\hline Pipe Entrance, Trial 1 & 02 & 09 & 61 & -12 & -10 & 02 & -14 & 11 & 25 \\
\hline Pipe Emergence, Trial 1 & -05 & -02 & -03 & -04 & 16 & -03 & 04 & -02 & 35 \\
\hline Pipe Entrance, Trials 2, 3, 4 & -07 & -01 & -03 & -02 & 61 & -03 & -03 & -03 & 11 \\
\hline Pipe Emergence, Trials 2, 3, 4 & 01 & 46 & -06 & -07 & 70 & -04 & -03 & -05 & -07 \\
\hline Pipe Defecation & 03 & -03 & 02 & -06 & 15 & 00 & -02 & -23 & 06 \\
\hline Pipe Urination & 01 & -12 & 07 & 02 & 02 & 08 & 04 & -42 & -05 \\
\hline Circular Activity, No Bell & 11 & 03 & -02 & 70 & -01 & 10 & 06 & 05 & -03 \\
\hline Circular Activity, Bell & 07 & -06 & 01 & 78 & -07 & 02 & -02 & 03 & 01 \\
\hline Circular Activity Defecation & -14 & -06 & 06 & -01 & 03 & 31 & 01 & 00 & -02 \\
\hline Circular Activity Urination & 01 & -02 & -05 & -08 & -01 & 00 & 05 & 02 & -04 \\
\hline
\end{tabular}

*Adapted from Royce, Poley, and Yeudall (1973).

artificial selection for stress resistance. This selection process is also complicated by the fact that it is transmitted through females only.

Interpreting the interaction for Factor VIII, autonomic balance, is more difficult than for Factor VI. However, this strain reversal is also suggested for Factors VII and IX (see Fig. 1), with the result that it is more difficult to dismiss this as a chance occurrence. Thus, in one strain (C57BL) low emotionality confers a resistance to cannibalism, while in the other strain (BALB) low emotionality predisposes females to kill their offspring. If we consider that arousal functions in rodents often follow an inverted-U function (see Mos, Royce, \& Poley, 1973) and hypothesize that the generally more emotional BALB mice are initially in a higher state of arousal than C57BL, we may be able to explain this result. This would mean that some conditions in the breeding colony (perhaps induced by the pups themselves) would lower arousal from its optimal position in BALB animals, inducing stress and, consequently, cannibalism. For C57BL animals, on the other hand, the same conditions would raise arousal closer to its optimum level (i.e., lower stress) and confer a protection against cannibalism. Whether or not this interpretation is accepted, the observed relationships are still of significance. They strongly indicate that rigorous control over psychological stressors should be maintained in rodent breeding colonies for at least two reasons: the practical reason of attempting to successfully raise animals to maturity and the scientific reason of avoiding the introduction of unknown sources of genetic selection.

\section{REFERENCES}

Ader, R., \& Grota, L. J, Rhythmicity in the maternal behaviour of Rattus norvegicus. Animal Behaviour, 1970, 18, 144-150. Menear, J, R. To study an animal response to sonic boom. Agricultural Engineering, 1968, 49, 86.

Mos, L., Royce, J. R., \& Poley, W. The effect of postweaning stimulation on factors of mouse emotionality. Developmental Psychology, 1973, 8, 229-239.

Pilgrim, H. I., \& Parks, R. C. Foster nursing of germ free mice. Laboratory Animal Care, 1968, 13, 346-351.

Poley, W., \& Royce, J. R. Genotype, maternal stimulation, and factors of mouse emotionality. Joumal of Comparative Physiological Psychology, 1970, 71, 246-250.

Poley, W., \& Royce, J. R. Behavior genetic analysis of mouse emotionality: II. Stability of factors across genotypes. Animal Learning \& Behavior, 1973, 1, 116-120.

Ressler, $R$. H. Parental handling in two strains of mice reared by foster parents. Science, 1962, 137, 129-130.

Ressler, R. H. Genotype-correlated parental influences on two 
strains of mice. Journal of Comparative \& Physiological Psychology, 1966, 61, 264-267

Royce, J. R., Optimal stimulus parameters in avoidance conditioning of inbred strains of mice. Multivariate Behavioral R esearch, 1966, 1, 209-217.

Royce, J. R., Poley, W., \& Yeudall, L. T. Behavior genetic analysis of mouse emotionality: I. The factor analysis. Journal of Comparative \& Physiological Psychology, 1973, 83, 36-47.
Schlesinger, K, \& Griek, B. J. The genetics and biochemistry of audiogenic seizures. In G. Lindzey and $L$. D. Thiessen (Eds.), Contributions to behavior-genetic analysis: The mouse as a prototype. New York: Appleton-Century-Crofts, 1970.

(Received for publication February 12, 1974; revision received April 2,1974 .) 